\section{(6) OPEN ACCESS}

\title{
Increased risk of congenital heart disease in twins in the North of England between 1998 and 2010
}

\author{
K E Best, ${ }^{1}$ J Rankin ${ }^{1,2}$
}

${ }^{1}$ Institute of Health \& Society, Newcastle University, Newcastle upon Tyne, UK ${ }^{2}$ PHE: Regional Maternity Survey Office, Newcastle upon Tyne, UK

\section{Correspondence to} Professor Judith Rankin, Institute of Health \& Society, Baddiley-Clark Building, Newcastle University, Newcastle upon Tyne NE2 4AX, UK; judith.rankin@ncl.ac.uk

Received 17 March 2015 Revised 17 June 2015 Accepted 10 July 2015 Published Online First 28 September 2015

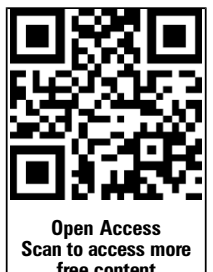

\section{CrossMark}

To cite: Best KE, Rankin J. Heart 2015;101:

$1807-1812$
ABSTRACT

Objective To examine the relative risk (RR) of congenital heart disease (CHD) in twins compared with singletons, according to chorionicity.

Methods Twins and singletons with CHD notified to the Northern Congenital Abnormality Survey between 1998 and 2010 were included in this population-based study. Information on chorionicity was obtained from the Northern Survey of Twins and Multiple Pregnancy. Prevalence was calculated as the number of cases occurring in live births, late miscarriages (20-23 weeks), stillbirths ( $\geq 24$ weeks) and terminations of pregnancy for fetal anomaly, per 10000 total births. The risk of CHD in twins compared with singletons was estimated using Poisson regression.

Results There were 399414 singleton births of which 2984 (0.7\%) had CHD. Among 11871 twin births, 154 $(1.3 \%)$ had CHD; one twin was affected by CHD in $2.5 \%$ of twin pregnancies. Of 8605 dichorionic (DC) births and 2317 monochorionic (MC) births, 96 (1.1\%) and $47(2.0 \%)$ were associated with CHD. Compared with singletons, twins were at significantly increased risk of $\mathrm{CHD}(\mathrm{RR}=1.73,95 \% \mathrm{Cl} 1.48$ to $2.04 ; \mathrm{p}<0.001)$. MC twins were at $82 \%$ significantly increased risk of $\mathrm{CHD}$ compared with $\mathrm{DC}$ twins ( $\mathrm{RR}=1.82,95 \% \mathrm{Cl} 1.29$ to 2.57; $p<0.001)$. The RR of severe and mild CHD was particularly high in $\mathrm{MC}$ twins compared with singletons (292\% increased risk, $\mathrm{RR}=3.92,95 \% \mathrm{Cl} 1.25$ to 12.30 , $\mathrm{p}=0.02$ and $207 \%$ increased risk, $\mathrm{RR}=3.07,95 \% \mathrm{Cl}$ 2.20 to $4.28 ; p<0.001)$.

Conclusions Compared with singletons, twins were at increased risk of CHD, the risk being substantially higher among $M C$ twins. This information is important for health professionals when counselling women with twin pregnancies.

\section{INTRODUCTION}

There is an increased risk of congenital anomalies in multiple compared with singleton pregnancies. ${ }^{1-4}$ The risk among twins that share a placenta, monochorionic (MC) twins, exceeds that of twins that do not share a placenta, dichorionic (DC) twins. ${ }^{1}$ The risk of congenital heart disease (CHD) among twins is less well researched. While several case series have investigated the prevalence of $\mathrm{CHD}$ in twins, ${ }^{5-8}$ few studies have compared the rate with singletons. ${ }^{149}$ Of those that have, the risk of CHD was significantly increased by between $47 \%$ and $63 \%$ in twins. ${ }^{1}{ }^{49}$ Even fewer studies have examined the risk of $\mathrm{CHD}$ by chorionicity. In Glinianaia et al's ${ }^{1}$ study, there was a $30 \%$ and $50 \%$ increased risk of CHD in MC and DC twins compared with singletons, but this only reached significance in DC twins. Herskind et al examined the relative risk (RR) in twins compared with singletons according to zygosity, a proxy for chorionicity given that all dizygotic twins are DC and approximately two-thirds of monozygotic twins are MC. Herskind et $a l^{9}$ reported significantly increased risks of 35\% and $30 \%$ in monozygotic and dizygotic twins, respectively.

The aim of this study was to examine the RR of $\mathrm{CHD}$ in twins compared with singletons, according to chorionicity and CHD severity.

\section{METHODS}

\section{Data sources}

The Northern Survey of Twin and Multiple Pregnancies (NorSTAMP) collects data on all multiple pregnancies to mothers residing in the North of England (figure 1). The North of England is a geographically defined area with a population of almost three million (with little immigration or emigration) and approximately 32000 births per year. Multiple pregnancies are ascertained from the prenatal dating scan, the 20 -week anomaly scan, and at delivery. ${ }^{10}$ In addition to basic maternal and fetal characteristics, chorionicity is recorded by NorSTAMP. Data on chorionicity is collected throughout pregnancy but the final diagnosis of chorionicity for twins of the same sex is based on placental examination and histology. ${ }^{10}$ If there is no pathological examination of the placenta, the diagnosis is made based on the prenatal ultrasound determination.

The NorSTAMP records are linked to the Northern Congenital Abnormality Survey (NorCAS). The NorCAS collects data on cases with congenital anomalies delivered to women residing in the North of England. Cases occurring in late miscarriages (20-23 weeks gestation), termination of pregnancy for fetal anomaly (TOPFA; any gestation), stillbirths ( $\geq 24$ weeks gestation) and live births are notified to NorCAS. Cases are notified from multiple sources including antenatal ultrasound, fetal medicine, cytogenetic laboratories, the regional cardiology centre, pathology and paediatric surgery, ensuring high case ascertainment. Up to eight congenital anomalies per case are recorded.

Cases are coded according to the International Classification of Diseases (ICD) V.10. The European Surveillance of Congenital Anomalies (EUROCAT, a network of 38 registers in 20 European countries) exclusion list for minor anomalies is employed. ${ }^{11}$

Data on the annual number of live and stillbirths to mothers residing in the North of England 


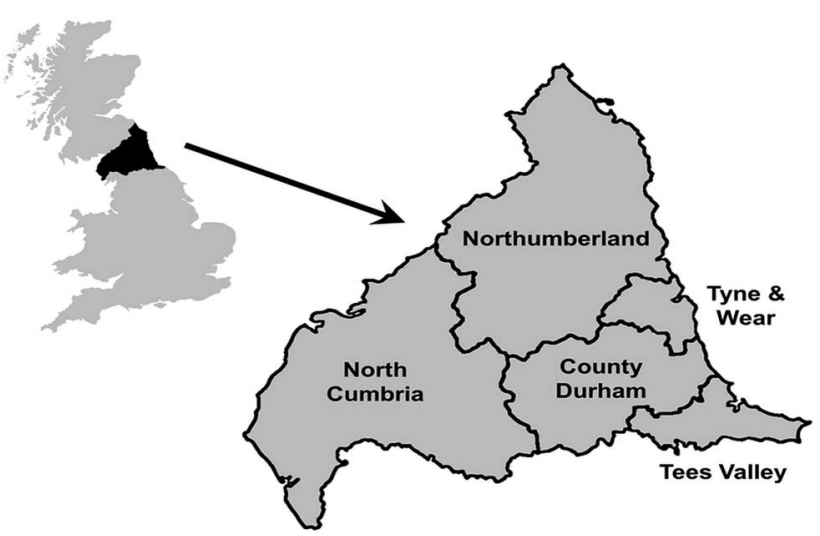

Figure 1 Map showing the region covered by the Northern Congenital Abnormality Survey (NorCAS) and the Northern Survey of Twin and Multiple Pregnancies (NorSTAMP).

(combined and by maternal age) was provided by the Office for National Statistics. Data on the annual number of twin live and stillbirths were provided by the NorSTAMP. The annual numbers of singleton births were calculated by subtracting the annual number of multiple births from the annual number of all births. Maternal age data were missing for 248 (2.1\%) twin pregnancies and these were excluded from the denominator for analysis of maternal age.

\section{Ethical approval}

Parental consent is required for NorSTAMP. The NorCAS has approval from the Confidentiality Advisory Group of the Health Research Authority (PIAG 2-08(e)/2012), to hold data without consent and ethics committee approval (09/H0405/48) to undertake studies involving the data.

\section{Case definition}

All cases with a final diagnosis of CHD (ICD 10: Q20-26) notified between 1 January 1998 and 31 December 2010 were included. Cases with a minor CHD only, such as patent ductus arteriosus (PDA) with a gestational age $<37$ weeks, were excluded. ${ }^{11}$ Cases known to occur with extra-cardiac anomalies (ie, congenital anomalies not of the cardiovascular system) are likely to have different aetiologies than cases with isolated CHD. For example, CHD occurring with chromosomal/genetic anomalies may result directly from chromosomal aneuploidy. ${ }^{12}$ These cases are likely to have different risk factors, such as increased maternal age. ${ }^{13} 14$ Analysis was performed on cases of isolated CHD only, to investigate the purest possible association between CHD and plurality.

\section{Case coding}

Twins were coded as MC or DC. Due to small case numbers, it was not possible to analyse the association between plurality and CHD according to CHD subtype. However, it was possible to analyse groups of CHD subtypes, which were classified according to severity. Based on the classification system outlined by Khoshnood et al, ${ }^{15}$ cases of CHD were categorised as severe, moderate and mild CHD. However, we also included double outlet RV, interrupted aortic arch and mitral valve anomalies. The groups of CHD subtypes are shown in table 1. Cases with multiple CHD subtypes were categorised according to the CHD in the highest severity group. Cases included in Q20-26 but not described in one of the severity categories (eg, PDA $\geq 37$ weeks gestation) remained unclassified.

Table 1 Frequency of CHD subtypes and severity categories according to plurality and chorionicity

\begin{tabular}{|c|c|c|c|c|}
\hline CHD subtype & $\begin{array}{l}\text { Twins (any chorionicity) } \\
\mathrm{N}(\% \text { of } 154)\end{array}$ & $\begin{array}{l}\text { Dichorionic twins } \\
\mathrm{N}(\% \text { of } 96)\end{array}$ & $\begin{array}{l}\text { Monochorionic twins } \\
\mathrm{N}(\% \text { of } 47)\end{array}$ & $\begin{array}{l}\text { Singletons } \\
N(\% \text { of } 2984)\end{array}$ \\
\hline Severe CHD & $7(4.6)$ & $4(4.2)$ & $3(6.4)$ & $132(4.4)$ \\
\hline Single ventricle & $2(1.3)$ & $1(1.0)$ & $1(2.1)$ & $15(0.5)$ \\
\hline Hypoplastic left heart & $2(1.3)$ & $1(1.0)$ & $1(2.1)$ & $76(2.6)$ \\
\hline Hypoplastic right heart & $3(2.0)$ & $2(2.1)$ & $1(2.1)$ & $41(1.4)$ \\
\hline Moderate CHD & $31(20.1)$ & $25(26.0)$ & $5(10.6)$ & $712(23.9)$ \\
\hline Pulmonary valve atresia & $5(3.3)$ & $5(5.2)$ & 0 & $32(1.1)$ \\
\hline Common arterial trunk & 0 & 0 & 0 & $20(0.7)$ \\
\hline Atrioventricular septal defect & $2(1.3)$ & $1(1)$ & $1(2.1)$ & $70(2.4)$ \\
\hline Aortic valve atresia/stenosis & $4(2.6)$ & $3(3.1)$ & $1(2.1)$ & $100(3.4)$ \\
\hline Transposition of the great vessels & $2(1.3)$ & $1(1.0)$ & $1(2.1)$ & $145(4.9)$ \\
\hline Tetralogy of Fallot & $6(3.9)$ & $5(5.2)$ & $1(2.1)$ & $117(3.9)$ \\
\hline Total anomalous pulmonary venous return & $2(1.3)$ & $2(2.1)$ & 0 & $34(1.1)$ \\
\hline Coarctation of aorta & $10(6.5)$ & $8(8.3)$ & $1(2.1)$ & $132(4.4)$ \\
\hline Double outlet RV & 0 & 0 & 0 & $18(0.6)$ \\
\hline Interrupted aortic arch & 0 & 0 & 0 & $11(0.4)$ \\
\hline Mitral valve anomalies & 0 & 0 & 0 & $33(1.1)$ \\
\hline Mild CHD & $106(68.8)$ & $63(65.6)$ & $35(74.4)$ & 1967 (69.9) \\
\hline Ventricular septal defect & $69(44.8)$ & 39 (40.6) & $25(53.2)$ & $1392(46.7)$ \\
\hline Atrial septal defect & $18(11.7)$ & $12(12.5)$ & $4(8.5)$ & $339(11.4)$ \\
\hline Pulmonary valve stenosis & $19(12.3)$ & $12(12.5)$ & $6(12.8)$ & $236(7.9)$ \\
\hline Other CHD & $10(6.5)$ & $4(4.2)$ & $4(8.5)$ & $173(5.8)$ \\
\hline Patent ductus arteriosus ( $\geq 37$ weeks) & $4(2.6)$ & $1(1.0)$ & $2(4.3)$ & $58(1.9)$ \\
\hline Total & $154(100.0)$ & $96(100.0)$ & $47(100.0)$ & $2984(100.0)$ \\
\hline
\end{tabular}

CHD, congenital heart disease. 


\section{Statistical analysis}

Total birth prevalence was calculated as the number of cases (in live births, late miscarriages, stillbirths or TOPFAs) per 10000 live and stillbirths (total births).

The unadjusted RR of CHD in twins compared with singletons was estimated using Poisson regression models with the number of cases of CHD as the outcome, $\log$ (total births) as the offset and plurality (singleton or twin) as an explanatory variable. Adjusted RRs were estimated by refitting the models to include year of delivery (continuous variable) and maternal age $(<20,20-29,30-34$ and $\geq 35$ years). The interaction between year of delivery and plurality was investigated by refitting the model with a cross-product term. The unadjusted RRs of CHD associated with maternal age and year of delivery were also estimated using Poisson regression.

All statistical analyses were performed in Stata V.13; $p<0.05$ was considered statistically significant.

\section{RESULTS}

Between 1998 and 2010, there were 399414 singleton pregnancies and 6101 twin pregnancies that resulted in (at least one) live or stillbirth in the North of England. This equated to 11871 total births, given that only one twin was live or stillborn in 331 pregnancies. Of the twins, 4359 pregnancies $(8605$ births, 72.5\%) were DC and 1170 pregnancies (2317 births, $19.5 \%$ ) were MC, leaving 542 pregnancies (949 births, 8.0\%) with unknown chorionicity. The proportion of twin pregnancies increased from $2.6 \%$ in 1998 to $2.9 \%$ in 2010 , although this did not reach statistical significance (test for trend: $p=0.07$ ).

There were 4160 cases of CHD delivered between 1998 and 2010: 3965 singletons and 187 twins. Of the 187 twins with CHD, 114 (61.0\%) were DC, 60 (32.1\%) were MC and 13 (7.0\%) had unknown chorionicity.

\section{Extra-cardiac anomalies}

Of the singletons with CHD, 700 (17.7\%) occurred with chromosomal/genetic anomalies and $281(7.1 \%)$ with structural anomalies. Of the twins with CHD, 15 (8.0\%) occurred with chromosomal/genetic anomalies and 18 (9.6\%) with structural anomalies. Twins with CHD were at significantly decreased risk of chromosomal/genetic anomalies compared with singletons $(\mathrm{RR}=0.45,95 \% \mathrm{CI} 0.28$ to $0.74 ; \mathrm{p}<0.001)$. The risk of structural anomalies was not significantly different in twins compared with singletons ( $R R=1.22,95 \%$ CI 0.77 to $1.91 ; \mathrm{p}=0.40)$. Cases with extra-cardiac anomalies were excluded from further analysis, leaving 2984 singletons and 154 twins with isolated CHD.

\section{CHD subtypes, severity and concordance}

Of the singletons with isolated CHD, 132 (4.4\%) had severe CHD, 721 (23.9\%) had moderate CHD, 1967 (65.9\%) had mild CHD and 173 (5.8\%) were of unclassified severity. Of the twins, 7 (4.5\%) had severe CHD, 31 (20.1\%) had moderate CHD, 106 (68.8\%) had mild CHD and 10 (6.5\%) were of unclassified severity. The distribution of CHD subtypes and severity categories according to chorionicity is shown in table 1 .

There were eight sets of twins with concordant CHD (four with the same subtype), of which six were DC and two were MC.

\section{Birth prevalence}

There were 2984 singletons with isolated CHD, a prevalence of 74.7 per 10000 total births (table 2); $0.7 \%$ of singleton pregnancies were associated with CHD. There were 154 twins with CHD, a prevalence of 129.7 per 10000 total births; in $2.5 \%$ of twin pregnancies, at least one twin was affected by isolated CHD. Of the 154 twins with CHD, 96 occurred in DC and 47 in MC pregnancies, giving prevalence rates of 111.6 and 202.8 per 10000 total births, respectively. At least one twin was affected by isolated CHD in 2.2\% of DC twin pregnancies and $4.0 \%$ of MC twin pregnancies. The prevalence of severe, moderate and mild CHD are shown in table 2 by chorionicity. At least one twin was affected by severe, moderate and mild CHD in $0.1 \%, 0.5 \%$ and $1.7 \%$ of twin pregnancies, respectively.

\section{Maternal age}

Among singletons, there was no evidence that $\mathrm{CHD}$ was associated with maternal age $(p=0.53)$. Among twins, the association between CHD and maternal age was of borderline significance $(p=0.07)$, with mothers aged $<20$ years having an increased risk of a pregnancy associated with CHD than mothers aged 20-29 years (table 3). Among DC twins, there was no evidence of an association between maternal age and CHD ( $p=0.41)$ (table 3). Among MC twins, there was evidence of an association between maternal age and CHD $(p=0.01)$, with mothers aged $<20$ years being at increased risk of a pregnancy associated with CHD compared with mothers aged 20-29 years (table 3 ).

\section{Trends}

The risk of CHD among singletons decreased significantly by $2 \%$ per year $(\mathrm{p}<0.001)($ table 3$)$. There was no evidence of a trend in CHD prevalence over time in twins (any chorionicity) $(p=0.95)$ or in DC twins $(p=0.09)$. In MC twins, the risk of CHD increased significantly by $8 \%$ per year $(p=0.04)$ (table 3$)$.

\section{Risk of CHD in twins versus singletons}

Twins were at $73 \%$ significantly increased risk of CHD compared with singletons $(p<0.001)$ (table 4$)$. There was a $78 \%$, $46 \%$ and $81 \%$ increased risk of severe, moderate and mild CHD in twins (any chorionicity) compared with singletons

Table 2 Prevalence per 10000 total birth $(95 \% \mathrm{Cl})$ of CHD in twins and singletons, according to CHD severity and chorionicity

\begin{tabular}{llccc}
\hline & \multicolumn{1}{l}{ Twins } & & \\
\cline { 2 - 3 } CHD severity & Twins (any chorionicity) & Dichorionic twins & Monochorionic twins & Singletons \\
\hline All CHD & $129.7(110.2$ to 151.7$)$ & $111.6(90.5$ to 136.1$)$ & $202.8(149.4$ to 268.8$)$ & $74.7(72.1$ to 77.4$)$ \\
Severe CHD & $5.9(2.4$ to 12.2$)$ & $4.6(1.3$ to 11.9$)$ & $12.9(2.7$ to 37.8$)$ & $3.3(2.8$ to 3.9$)$ \\
Moderate CHD & $26.1(17.8$ to 37.0$)$ & $29.1(18.8$ to 42.9$)$ & $21.6(7.0$ to 50.3$)$ & $17.8(16.5$ to 19.2$)$ \\
Mild CHD & $89.3(73.2$ to 107.9$)$ & $73.2(56.3$ to 93.6$)$ & $151.1(105.4$ to 209.5$)$ & $49.2(47.1$ to 51.5$)$ \\
\hline CHD, congenital heart disease. & & &
\end{tabular}


Table 3 RR of CHD according to maternal age and year of delivery

\begin{tabular}{|c|c|c|c|c|}
\hline \multirow{2}{*}{$\begin{array}{l}\text { Maternal age at } \\
\text { delivery* }\end{array}$} & \multicolumn{4}{|l|}{ N, Unadjusted RR (95\% Cl) } \\
\hline & Twins (any chorionicity) & Dichorionic twins & Monochorionic twins & Singletons* \\
\hline$<20$ & $\begin{array}{l}\mathrm{N}=14 \\
\mathrm{RR}=1.93 \text { (0.96 to } 3.88)\end{array}$ & $\begin{array}{l}\mathrm{N}=5 \\
\mathrm{RR}=1.06(0.33 \text { to } 3.44)\end{array}$ & $\begin{array}{l}\mathrm{N}=8 \\
\mathrm{RR}=3.37(1.27 \text { to } 8.95)\end{array}$ & $\begin{array}{l}\mathrm{N}=290 \\
\mathrm{RR}=0.94 \text { (0.83 to } 1.07)\end{array}$ \\
\hline $20-29$ & $\begin{array}{l}\mathrm{N}=66 \\
\mathrm{RR}=1 \text { (reference) }\end{array}$ & $\begin{array}{l}\mathrm{N}=40 \\
\mathrm{RR}=1 \text { (reference) }\end{array}$ & $\begin{array}{l}\mathrm{N}=21 \\
\mathrm{RR}=1 \text { (reference) }\end{array}$ & $\begin{array}{l}\mathrm{N}=1491 \\
\mathrm{RR}=1 \text { (reference) }\end{array}$ \\
\hline $30-34$ & $\begin{array}{l}\mathrm{N}=40 \\
\mathrm{RR}=0.74(0.50 \text { to } 1.10)\end{array}$ & $\begin{array}{l}\mathrm{N}=25 \\
\mathrm{RR}=0.76 \text { (0.46 to } 1.26)\end{array}$ & $\begin{array}{l}\mathrm{N}=11 \\
\mathrm{RR}=0.64(0.31 \text { to } 1.33)\end{array}$ & $\begin{array}{l}\mathrm{N}=754 \\
\mathrm{RR}=1.04 \text { (0.95 to } 1.13)\end{array}$ \\
\hline$\geq 35$ & $\begin{array}{l}\mathrm{N}=34 \\
\mathrm{RR}=0.97(0.64 \text { to } 1.47)\end{array}$ & $\begin{array}{l}\mathrm{N}=26 \\
\mathrm{RR}=1.22(0.75 \text { to } 2.01)\end{array}$ & $\begin{array}{l}\mathrm{N}=7 \\
\mathrm{RR}=0.63(0.27 \text { to } 1.48)\end{array}$ & $\begin{array}{l}\mathrm{N}=422 \\
\mathrm{RR}=1.03 \text { (0.93 to } 1.15)\end{array}$ \\
\hline Year of delivery & $\mathrm{RR}=1.00(0.96$ to 1.04$)$ & $\mathrm{RR}=0.96(0.91$ to 1.02$)$ & $\mathrm{RR}=1.08(1.01$ to 1.18$)$ & $\mathrm{RR}=0.98$ (0.97 to 0.99$)$ \\
\hline
\end{tabular}

$(\mathrm{p}=0.135, \mathrm{p}=0.037$ and $\mathrm{p}<0.001$, respectively) (table 4$)$, although this only reached statistical significance for moderate and mild CHD.

MC twins were at $82 \%$ significantly increased risk of $\mathrm{CHD}$ compared with DC twins $(\mathrm{RR}=1.82$, 95\% CI 1.29 to 2.57 ; $\mathrm{p}<0.001)$. Compared with singletons, DC twins were at $49 \%$ significantly increased risk of CHD $(p<0.001)$ and $M C$ twins were at $172 \%$ significantly increased risk of CHD $(\mathrm{p}<0.001)$ (table 4). DC twins were at 41\%, 63\% and 49\% increased risk of severe, moderate and mild CHD, respectively (table 4), although this did not reach statistical significance for severe CHD ( $p=0.50, p=0.02$ and $p=0.002$, respectively). MC twins were at $292 \%$ significantly increased risk of severe CHD $(p=0.02)$ and $207 \%$ significantly increased risk of mild CHD $(p<0.001)$. There was no significant effect among moderate CHD ( $\mathrm{p}=0.64)$ (table 4).

Adjusting for year of delivery and maternal age had little impact on the RR of CHD in twins compared with singletons (table 4).

When considering all twins (any chorionicity) and DC twins, the interaction between year of delivery and plurality was not significant $(p=0.45$ and $p=0.52$, respectively). Among $\mathrm{MC}$ twins, there was a significant interaction between year of delivery and plurality $(p=0.01)$, with the RR of CHD in MC twins compared with singletons increasing over the study period (interaction term: $\mathrm{RR}=1.11,95 \% \mathrm{CI} 1.02$ to 1.20 ).

\section{DISCUSSION}

In this population-based study, we found a $73 \%$ increased risk of $\mathrm{CHD}$ in twins compared with singletons. MC twins were at $172 \%$ and DC twins were at $49 \%$ increased risk of CHD compared with singletons.

This is one of few studies to examine the RR of CHD in twins compared with singletons. The primary strength of this study is the use of population-based data derived from an established, high-quality, congenital anomaly register. Multiple sources notify the register of cases, ensuring high case ascertainment. Accurate diagnoses are achieved by the review of complex cases by paediatric pathologists and clinical geneticists and, where relevant, diagnoses are confirmed via postmortem. By linking to a population-based register of multiple pregnancies, we were able to estimate the RR of CHD according to chorionicity, which few studies have accomplished. ${ }^{19}$ Data on chorionicity is unlikely to be misclassified, given that the final diagnosis of like-sex twins is based on placental examination and histology.

A further strength is that CHD occurring in TOPFAs, late miscarriages and stillbirths were included. TOPFAs are less frequent in twin compared with singleton pregnancies, so had they been excluded; our RR of CHD associated with twins may have been overestimated. ${ }^{16}$ Stillbirth is more common in twin compared with singleton pregnancies, so excluding stillbirths could have diluted the RR of CHD. ${ }^{16}$

We examined the RR of CHD in twins versus singletons adjusted for confounding factors. Year of delivery is a potential confounder given that the twinning rate increased slightly over the study period. Maternal age may have been a confounder due to the association between increased maternal age and multiple pregnancy ${ }^{17}$ and the increased risk of CHD with increased maternal age, which is reported in some, but not all studies. $^{18-21}$

This study has some limitations. First, the sample size was small meaning non-significant results could have resulted from type II errors. Among MC twins, the significant association with maternal age in under 20 s should be interpreted cautiously due to low case numbers. Additionally, we were only able to examine severity categories as opposed to subtypes. As NorSTAMP requires parental consent, chorionicity data were not available for all twins. However, chorionicity data were missing for just $7 \%$ of cases and $8 \%$ of the denominator. Moreover, eight sets of twins with CHD were from the same pregnancy. This violates one of the assumptions of Poisson regression, that all observations should be independent. However, after excluding eight cases (one out of each set), the $\mathrm{RR}$ reduced only slightly (unadjusted $\mathrm{RR}=1.63$, 95\% CI 1.38 to $1.93 ; \mathrm{p}<0.001, \mathrm{RR}=1.40,95 \% \mathrm{CI} 1.14$ to 1.73 ; $\mathrm{p}=0.002$ and $\mathrm{RR}=2.60,95 \%$ CI 1.94 to $3.49 ; \mathrm{p}<0.001$ for all twins (any chorionicity), DC twins and MC twins, respectively). We did not have data on zygosity as these are not recorded on the NorSTAMP. However, chorionicity can be used as a proxy zygosity given that all MC twins are monozygotic and most ( 90\%) DC twins are dizygotic. ${ }^{8}$ Lastly, we were not able to investigate the risk associated with assisted reproductive technology (ART) as the registers are not able to hold this information.

Our $73 \%$ significant increased risk of CHD in twins compared with singletons is slightly greater than previously reported. $^{149}$ Mastroiacovo et $\mathrm{l}^{4}$ reported an increased risk of 51\% in Europe and Latin America (1978-1995), Glinianaia 


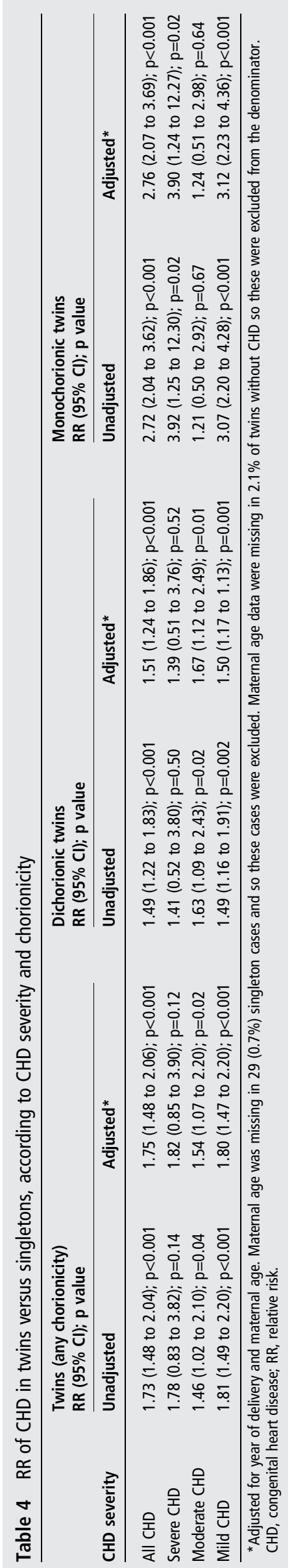

et $a l^{1}$ reported an increased risk of $47 \%$ in the North of England (using a subset of the present data, 1998-2002) and Herskind et $a l^{9}$ reported an increased risk of $63 \%$ in Denmark (1977-2001). In our study, the RR of CHD in MC twins increased over the study period, so we may have found a greater RR due to our more recent study period. The increase in risk may be a result of increased screening of MC twins, given that the increased risk of congenital anomaly in MC twins has become more widely known over time. In the UK, the National Institute for Health and Care Excellence (NICE) ${ }^{22}$ guidelines were updated in 2011 to recommend at least nine antenatal scans for MC twin pregnancy. This may have had particular impact if diagnosis of mild CHD improved, due to technical developments.

We identified a greater risk of CHD in MC compared with DC twins. Conversely, in the study by Glinianaia $e t a l,{ }^{1}$ there was no significant difference in the RR by chorionicity, but just nine cases in MC twins were examined. Herskind et $a l^{9}$ estimated the RR of CHD according to zygosity, finding no significant difference in risk. However, bias may have been incurred due to missing zygosity information. Indeed, in their cases with missing zygosity, the RR of CHD was greater than that of all twins ( $\mathrm{RR}=2.41,95 \% \mathrm{CI} 2.07$ to 2.80$)$. Had a higher proportion of monozygotic twins had missing zygosity, this could partly explain why monozygotic twins were not at increased risk. Lastly, Herskind $e t a l^{9}$ included only live births, which may have impacted on their results.

We found a significant increased risk of moderate and mild CHD in twins (any chorionicity) compared with singletons. While the risk of severe CHD was increased, it did not reach statistical significance, likely due to low power. The RR was significant among MC twins, due to the larger effect size, although this should be interpreted cautiously due to low sample size. Several studies have examined the RR of CHD in multiples compared with singletons by CHD subtype. ${ }^{3} 49$ Significant increased risks have been reported for ventricular septal defect (VSD), atrial septal defect, single ventricle, tetralogy of Fallot, atrioventricular septal defect and coarctation of aorta, although the effect sizes vary by study. Herskind et al uniquely examined subtypes according to zygosity, but could only examine VSD in monozygotic twins due to low sample size, finding a $73 \%$ increased risk compared with singletons.

The aetiology of CHD is becoming more researched and is hypothesised to be of both genetic and haemodynamic origin..$^{23}$ The aetiology of the increased risk of CHD in twins is unresolved. Twin to twin transfusion in MC twins was identified as an important risk factor for CHD. ${ }^{8}{ }^{24}$ However, this does not explain why there would be an increased risk in DC twins. Others hypothesise that placental vascular anastomoses between the monozygotic co-twins' circulations may lead to fluctuations in blood flow during fetal heart development, causing CHD. ${ }^{25}{ }^{26}$ If the aetiology of CHD in twins is predominantly haemodynamic as opposed to genetic, this may explain why chromosomal anomalies were less common in twins with CHD compared with singletons. Alternatively, monozygotic twinning itself is hypothesised to be part of a morphogenic anomaly which leads to a congenital anomaly. ${ }^{27}$ Given that all MC twins are monozygotic and around 10\% of DC twins are monozygotic, this might explain why there was an increased risk in both MC and DC twins and why the effect size was greater in MC twins. However, previous research also found an increased risk among dizygotic twins. ${ }^{9}$ Perhaps the increased risk in DC twins could be related to the use of ART, which can result in twin pregnancy and has been linked to an increased CHD prevalence. ${ }^{28}$ 


\section{Key messages}

What is already known on this subject?

- Twins, in particular monochorionic twins, are at increased risk of congenital anomaly compared with singletons.

- Existing research suggests there is an increased risk of congenital heart disease (CHD) in twins compared with singletons.

- The effect of chorionicity and CHD severity on the increased risk in twins is less well researched.

What might this study add?

- Twins are at $73 \%$ increased risk of CHD compared with singletons.

- The risk among monochorionic (MC) twins exceeded that of dichorionic twins, with an increased risk of $82 \%$.

- The prevalence of CHD in MC twins has increased over time.

How might this impact on clinical practice?

- Twin pregnancies, in particular MC twin pregnancies, require increased antenatal surveillance for CHD.

- This information is important for health professionals when counselling women with a twin pregnancy.

Acknowledgements We thank Dr Svetlana Glinianaia for her helpful comments on the manuscript. We thank the link clinicians for their continued collaboration and support of the NorCAS and NorSTAMP.

Contributors Both authors have read and approved the final version of the manuscript before submission. JR conceived the project and critically reviewed the manuscript. KEB performed the data analysis and drafted the manuscript. Both authors were involved in the interpretation of the data and have given final approval to submit the paper.

Funding This work was supported by a British Heart Foundation studentship (FS/ 12/23/29511 to KEB). NorCAS is currently funded by Public Health England.

Competing interests None declared.

Ethics approval CAG.

Provenance and peer review Not commissioned; externally peer reviewed.

Open Access This is an Open Access article distributed in accordance with the terms of the Creative Commons Attribution (CC BY 4.0) license, which permits others to distribute, remix, adapt and build upon this work, for commercial use, provided the original work is properly cited. See: http://creativecommons.org/ licenses/by/4.0/

\section{REFERENCES}

1 Glinianaia SV, Rankin J, Wright C. Congenital anomalies in twins: a register-based study. Hum Reprod 2008:23:1306-11.

2 Tang $Y, M a C X$, Cui W, et al. The risk of birth defects in multiple births a population-based study. Matern Child Health J 2006;10:75-81.

3 Li SJ, Ford N, Meister K, et al. Increased risk of birth defects among children from multiple births. Birth Defects Res A Clin Mol Teratol 2003;67:879-85.
4 Mastroiacovo $\mathrm{P}$, Castilla EE, Arpino $\mathrm{C}$, et al. Congenital malformations in twins: an international study. Am J Med Genet 1999:83:117-24.

5 Herberg U, Gross W, Bartmann P, et al. Long term cardiac follow up of severe twin to twin transfusion syndrome after intrauterine laser coagulation. Heart 2006;92:95-100.

6 Karatza AA, Wolfenden JL, Taylor MJ, et al. Influence of twin-twin transfusion syndrome on fetal cardiovascular structure and function: prospective case-control study of 136 monochorionic twin pregnancies. Heart 2002:88:271-7.

7 Lopriore E, Bokenkamp R, Rijlaarsdam M, et al. Congenital heart disease in twin-to-twin transfusion syndrome treated with fetoscopic laser surgery. Congenit Heart Dis 2007:2:38-43.

8 Manning N, Archer N. A study to determine the incidence of structural congenital heart disease in monochorionic twins. Prenat Diagn 2006:26:1062-4.

9 Herskind AM, Pedersen DA, Christensen K. Increased prevalence of congenital heart defects in monozygotic and dizygotic twins. Circulation 2013;128: $1182-8$.

10 Glinianaia SV, Rankin J, Sturgiss SN, et al. The North of England survey of twin and multiple pregnancy. Twin Res Hum Genet 2013;16:112-16.

11 European Surveillance of Congenital Anomaly Registers (EUROCAT). EUROCAT Guide 1.4. 2014. [http://www.eurocat-network.eu/aboutus/datacollection/ guidelinesforregistration/guide1_4]

12 Richards AA, Garg V. Genetics of congenital heart disease. Curr Cardiol Rev 2010;6:91.

13 Snijders RJM, Sebire NJ, Nicolaides KH. Maternal age and gestational age-specific risk for chromosomal defects. Fetal Diagn Ther 1995;10:356-67.

14 Hook EB. Rates of chromosome abnormalities at different maternal ages. Obstet Gynecol 1981;58:282-5.

15 Khoshnood B, Loane M, Garne E, et al. Recent decrease in the prevalence of congenital heart defects in Europe. J Pediatr 2012;162:108-13.

16 Boyle B, McConkey R, Garne E, et al. Trends in the prevalence, risk and pregnancy outcome of multiple births with congenital anomaly: a registry-based study in 14 European countries 1984-2007. BJOG 2013;120:707-16.

17 Blondel $B$, Kaminski $M$. The increase in multiple births and its consequences on perinatal health. J Gynecol Obstet Biol Reprod (Paris) 2002;31:725-40.

18 Forrester MB, Merz RD. Descriptive epidemiology of selected congenital heart defects, Hawaii, 1986-1999. Paediatr Perinat Epidemiol 2004;18:415-24.

19 Miller A, Riehle-Colarusso T, Siffel $C$, et al. Maternal age and prevalence of isolated congenital heart defects in an urban area of the United States. Am J Med Genet A 2011;155A:2137-45.

20 Cedergren MI, Kallen BAJ. Obstetric outcome of 6346 pregnancies with infants affected by congenital heart defects. Eur I Obstet Gynecol Reprod Biol 2006:125:211-16

21 Pradat $\mathrm{P}$, Francannet $\mathrm{C}$, Harris JA, et al. The epidemiology of cardiovascular defects, part I: a study based on data from three large registries of congenital malformations. Pediatr Cardiol 2003;24:195-221.

22 National Institute for Health and Care Excellence (NICE). Multiple pregnancy: the management of twin and triplet pregnancies in the antenatal period. NICE Guidelines 2011.

23 Bruneau BG. The developmental genetics of congenital heart disease. Nature 2008:451:943-8.

24 Bahtiyar MO, Dulay AT, Weeks BP, et al. Prevalence of congenital heart defects in monochorionic/diamniotic twin gestations: a systematic literature review. I Ultrasound Med 2007:26:1491-8.

25 Hall JG. Twinning. Lancet 2003;362:735-43.

26 Pharoah POD. Causal hypothesis for some congenital anomalies. Twin Res Hum Genet 2005;8:543-50

27 Jones KL, Jones MC, del Campo M. Smith's recognizable patterns of human malformation. Elsevier Health Sciences, 2013.

28 Tararbit K, Houyel L, Bonnet D, et al. Risk of congenital heart defects associated with assisted reproductive technologies: a population-based evaluation. Eur Heart $J$ 2011:32:500-8 